\title{
Exploring Opportunities for Public Health Graduates in Government Health System in Nepal
}

\author{
Khanal $\mathrm{P}^{1}$, Mishra SR ${ }^{2}$
}

${ }^{2}$ Research Officer, Manmohan Memorial Institute of Health Sciences, Nakkhu, Lalitpur

\begin{abstract}
Nepal has a history of nearly three decades of public health education. Public health graduates are working under different capacities at governmental and non governmental organizations. If the health system can utilize this human resource, this will contribute to health system strengthening in Nepal. The objective of this paper is to explore the opportunities for public health graduates in government health system in Nepal. MoHP needs to expand opportunities for public health graduates in different areas within government system. Recruiting district level supervisors from bachelor in public health background would enhance performance because of their knowledge and skills on areas like district health management, research, public health administration, health economics and medical sociology as compared to those with certificate level education on General medicine currently being recruited. In the meantime this will create hundreds of job placements in district health system for job aspirants. Role of community health inspectors needs to be made clear and sanctioned at the district and peripheral level. Also, there is necessity of environmental health technicians, health educators, health economists and other types of health personnel. It is equally necessary to establish environmental health, occupational health, urban health, health care waste management, mental health and oral health units at district level. The other areas where public health graduates can work as health officers are District Development committee, Municipality, Women and Child office and Water and Sanitation Division Office. The public health community including its professional organization Nepal Public Health Association should advocate for the professional rights and contribute to create opportunities for public health graduates.
\end{abstract}

Keywords: public health education; opportunities; health system; Nepal.

Submitted: 10 August 2014; Revised: 22 September 2014; Accepted: 25 September 2014

\section{Introduction}

Human Resource in Health in the government sector contributes to about one-third of the total work force in the civil service (1). Different constraints including two decades old organizational structure and sanctioned posts, substantial proportion of vacant positions, disinterest of health workers to work in rural areas, increasing imbalance between demand and supply of specialized health workers exist in the health sector of Nepal. There is more than twenty-five thousands workforce under MoHP (2). Public Health Officers and Administrators are vital workforce of health system in Nepal; the job specification of whom requires bachelor and master's degree in public health respectively. They are primarily responsible for health planning, monitoring and supervision of public health programs. This workforce contributes to about 0.92 percent of the total 24,477 sanctioned posts for health workers in health facilities (3). This paper discusses about public health education in Nepal, current absorption of public health graduates in the government health system and explores the opportunities for public health graduates in the government health system in Nepal.

\section{Public health education in Nepal}

IOM, Tribhuvan University started Bachelor degree in Public Health from 1986 A.D. and M.Sc. Public Health Program from 1991 A.D. M.Sc. program was later converted to MPH program in 1998 A.D (4). The purpose of the bachelor level public health program is to produce professional public health specialists with the highest possible technical and managerial competence in district level health programs, including problem identification, planning, implementing, training, health education, and research, who can serve in different types of positions at national, regional, zonal, district or local levels. Such specialists will be needed in various kinds of governmental or non-governmental health agencies, hospitals, schools and institutions (5). The MPH curriculum in Nepal is expected to track public health professionals to take organizational leadership for assuring better health management and improving quality of life of the people through better quality health service delivery. IOM has also started PhD. program from 2011 A.D. for those who intend to pursue or advance a professional practice career in Public Health.

Two universities namely Purbanchal University and Pokhara University have also started BPH program in 2002 A.D. and 2005 A.D. respectively. BPKIHS, an autonomous health science university, started Master's Degree

\section{Correspondence:}

${ }^{1}$ Pratik Khanal

MPH Candidate

Maharajgunj Medical Campus, Institute of Medicine Email: khanal_pratik@yahoo.com 
in Public Health Program in 2005 A.D (6). Patan Academy of Health Science is also expected to offer MPH program in the near future (7). Institute of Medicine has started to provide specialized public health education namely Master degree in Health Promotion and Education and Master Degree in Public Health Nutrition along with generalized MPH from the year 2014 A.D (8).

\section{Current production of public health graduates}

Three universities and one autonomous health institution provides public health education. Annual production of public health under graduates, post graduates and doctorates is one thousand, forty one and two respectively. (Table 1)

\section{Current deployment of public health graduates in the government health system} There are sixteen District Public Health Offices and fifty nine District Health Offices (9). The basic difference between these two kinds of offices is that the latter comprises of both district hospital and public health section while the former looks after the public health, not the hospital administration. District Public Health Offices are headed by gazetted $2^{\text {nd }}$ class Public Health Administrator of Health Inspection Group. District Health Offices are headed by either Medical Superintendent of district hospital or Public Health Officer, whoever be the seniormost between two. Thus, there are 75 positions (59 gazetted $3^{\text {rd }}$ class and 16 gazetted $2^{\text {nd }}$ class) in the district health system for the public health graduates.

In the Regional Health Directorate (RHD), there is a position for Public Health Administrator and Public Health Officer. According to the Operating Manual of Department of Health Services, the organogram of the RHD shows the positions, each for Family Planning Officer, Planning Officer, Malaria Officer, Entomologist, Health Inspector and Supervision Officer in the Health Inspection group, which actually is not in practice (2). Positions like Nutrition Officer, Parasitologist have been also mentioned in the Nepal Health Service Regulations as they are not officer level entry positions. There are no positions for public health graduates in other regional level health facilities like Regional Medical Store and Regional Health Training Centre.

There are seven divisions and five centers under Department of Health Services. A total of 18 positions are sanctioned for Public Health Officers and Administrators in Department of Health Services.

There are six divisions under MoHP which also absorb the public health graduates under Health Inspection Group (Table 3).

\section{Future prospects}

A set back for the health system in the last decade was that there was no absorption of public health graduates at officer level position. Nepal Health Service Act- Fourth amendment opened the door for vacancy by making provision of Reservation, Internal Competition and Com- petency and experience based evaluation in addition to seats in open category.

However, there are limited opportunities for public health in the government sector. The system is still running as per the organogram designed more than two decades back while the population has increased from 18.4 to 26.4 million over the time.

At the district level, different programs are supervised by district supervisors, the entry criterion of which is Proficiency of Certificate level in General Medicine. There are two positions of Health Assistant, one for $\mathrm{IMCl}$ and other for Nutrition program. Likewise, Family Planning Supervisor, Tuberculosis and Leprosy Assistant, Immunization Supervisor position have been placed for implementing specific public health programs. Public Health Nurse, the entry criteria of the position being Certificate level in Nursing, manages the Safe Motherhood program (11). These positions are managerial which requires monitoring, evaluation and supervisory skills and thorough knowledge of the district as well as national health system. Graduates in public health, whose course duration are of 3 or 4 years and the curriculum equipped with contents like Public Health Administration, Health Management, District Health Management Field Practice ranging from one to two months, Health Economics, Research both theory and practical, are the best cadres for these position which also fulfill the notion of the government to develop specialized human resource for health for different positions. So, positions like Child Health Officer, Nutrition Officer, Disease Control Officer, Health Education and Training Officer, Family Health Officer, Planning, Monitoring and Evaluation Officer should be created at the district level which absorbs specialized human resource for health. The qualification for the positions of DHOs/DPHOs must be Masters Degree in Public Health.

A position for Health Assistant can be allocated for each program to assist the program heads. This amendment in the health system will help to better functioning of the district health management services and similar can be done at Regional and centre level. Post graduates in public health with health science background do not enjoy the same privilege as MBBS with MPH to work under Public Health Administration group of Nepal Health Service Act. This is a barrier to public health and nursing graduates with MPH degree to work as administrators, Regional directors, division and centre heads. Moreover, discrimination exists in the entry criteria for officer level cadres for medical ( $8^{\text {th }}$ level) and others like public health, nursing or pharmacy ( $7^{\text {th }}$ level) (12). This discriminatory system will end the aspiration of the latter of being the Directorate General and the Secretary of MoHP. There are also limited positions for public health administrator at ninth and eleventh level which blocks the career development of public health officers/administrators. Thus, there is a necessity to increase the number of posts to motivate this workforce and also merge public health officers and administrators into public health administration group as they basically perform managerial and administrative function. 
Exploring Opportunities for Public Health Graduates in Government Health System in Nepal

\begin{tabular}{|c|c|c|c|c|}
\hline University & Program & $\begin{array}{l}\text { Number of } \\
\text { institutions }\end{array}$ & Name of institution & Annual Intake \\
\hline Tribhuvan & $\mathrm{BPH}$ & 3 & MMC (IOM), MMIHS and CMC & $40+20+20=80$ \\
\hline \multirow[t]{4}{*}{ Univesity } & MPH & 3 & $\begin{array}{l}\text { MMC, CMC } \\
\text { and NMCTH, Birgunj }\end{array}$ & $(20+7+4)=31$ \\
\hline & MHPE & 1 & MMC (IOM) & 10 \\
\hline & MPHN & 1 & MMC (IOM) & 5 \\
\hline & PhD & 1 & MMC (IOM) & 2 \\
\hline Pokhara & $\mathrm{BPH}$ & 5 & $\begin{array}{l}\text { School of Health and } \\
\text { Allied Science } \\
\text { LA Grande, Nobel, CIST } \\
\text { and NOC }\end{array}$ & $5^{*} 40=200$ \\
\hline Purbanchal & $\mathrm{BPH}$ & 18 & $\begin{array}{l}\text { NIHS, NAMS, YHSA, VCHS, } \\
\text { KCHS, Little Buddha, Om Health, } \\
\text { Asian, Hope, Koshi Health, Shree } \\
\text { Medical, Unique, Saptarishi, Oasis, } \\
\text { Sanjeevani, Edenberg, Birat Health, } \\
\text { Chakrabati }\end{array}$ & $18^{*} 40=720$ \\
\hline BPKIHS & MPH & 1 & BPKIHS & 10 \\
\hline
\end{tabular}

Source: NHPC; TU; POU; PU; BPKIHS

Table 2: Sanctioned posts under Department of Health Services

\begin{tabular}{lll}
\hline S.N. & Post & Number of positions \\
\hline 1. & Director $^{*}$ & 1 \\
2. & Public Health Administrator & 8 \\
3. & Public Health Officer & 9 \\
\hline
\end{tabular}

*1 post of director for both Health Inspection and Public Health Administration group

Source: Personnel Administration Section, Department of Health Services

Table 3: Sanctioned posts under MoHP

\begin{tabular}{lll}
\hline Divisions under MoHP & Name of the section & Number of posts \\
\hline Administrative & - & - \\
Planning, Policy and & International Cooperation, Scholarship & $1(\mathrm{PHA})$ \\
International Cooperation Division & and Coordination & $1(\mathrm{PHO})$ \\
Curative Service Division & Disease Control and Blood Transfusion & $1(\mathrm{PHA})$ \\
Public Health Administration, & Public Health Administration & $1(\mathrm{PHA})$ \\
Monitoring and Evaluation Division & Monitoring and Evaluation & $1(\mathrm{PHO})$ \\
Population Division & Population Management & $1(\mathrm{PHA})$ \\
& Population Studies and Research & - \\
HR and Financial Management & - &
\end{tabular}

Source: Operating Manual for Department of Health Services 2011

Table 4: Proposed technical positions at District Health Office

\begin{tabular}{llll}
\hline Technical Positions & Program & Qualification & Number \\
\hline District (Public) Health Officer & Chief & MPH & 1 \\
Child Health Officer & Immunization, IMCI, & BPH & 1 \\
& CB-NCP & & \\
Nutrition Officer & Nutrition & BPH & 1 \\
Disease Control Officer & TB, Leprosy, Vector & BPH & 1 \\
& Control, HIV, Epidemic & \\
Health Education and Training Officer & NCD, Health Promotion, Training & BPH & 1 \\
Family Planning and Population Officer & FP, Population. FCHV, PHC-ORC & BPH & 1 \\
Safe Motherhood Officer & Safe motherhood, Safe abortion, ASRH BN/BSc. Nursing & 1 \\
Planning, Monitoring and Evaluation Officer & Planning, Integrated Supervision & BPH & 1 \\
Logistics Officer & Logistics management & B Pharm. & 1
\end{tabular}

Similarly, qualification for the position of Health Education Trainer $\left(7^{\text {th }}\right.$ level) under Health Education group as men- tioned in Nepal Health Service Regulations is Bachelor in Health Education or Post graduate Diploma or equiva- 
lent (12). But, neither public health graduates nor BEd. (Health) can compete for this position. Recently, IOM has started Master in Health Promotion and Education which will fulfill the shortage of health education administrators. But the entry criterion for officer level health education trainer should be health science graduates.

The newly introduced National Health Policy has envisioned the position of Community/Public Health Inspector in each constituency. It means as per the present context of our national structuring, two hundred and forty public health graduates will join the government workforce in the near future (13). Service Operation Directives for Community Health Inspectors 2070 which has been formed to mobilize contractual positions of Community Health Inspectors has kept the objective of health promotion and safe guarding the health security. The thematic work areas are Promotion of healthy foods, safe drinking water and sanitation; Sensitization on harmful effects of food additives and pesticides; Promotion of oral health, hand washing, ODF, Reproductive and Child health; NCD, tobacco and alcohol control; individual, family and environmental health; rationale use of drugs; support to National health programs at the community level (14). This position, if kept permanent, will ensure better community health.

Stakeholder perceptions on issues for inclusion in new national health policy in a review carried out by MoHP has also mentioned to train more personnel that are deficient in health care market like environmental health technicians, health educators, health economists and other types of health personnel. Similarly, deployment of nutrition supervisors at the district level, improving the system for inspecting water and food quality and establishment of environmental health, occupational health, urban health, health care waste management, mental health and oral health units at district level (15) are also included. These areas could be best addressed by public health graduates.

The other areas where public health graduates can work are District Development committee, Municipality and Women and Child office as well as Water and Sanitation Division Office. Health officer at DDC would contribute in areas like health planning, act as a liaison between government and non-government bodies in promotion of health. Similarly, Health Officer at Municipality will look after urban health and health welfare of the residents of municipality. Health officer at Women and child office will look after women and child health and welfare rights. Similarly, WASH Officer at Water and Sanitation Division Office will oversee water and sanitation program related to health.

\section{Conclusion}

Nepal has a history of nearly three decades of public health education. Public health graduates are working under different capacities at governmental and non governmental organizations. If the public health system can utilize more public health workforce, this will contribute to health system strengthening in Nepal. This requires the health system to expand opportunities for public health graduates in different areas like supervisory positions for different public health programs at district, regional and central level, public health inspectors, health educators, health economics, and environmental health and in other inter-linked agencies for better management of health services. Health problems we face now are not only clinical in nature but social and political brought about by weakened management system. Health managers with public health knowledge can fill this gap for which requires space for their absorption in adequate number. This would mean policy amendments which involves process like advocacy, continual lobbying at different levels. The public health community including its professional organization Nepal Public Health Association should advocate for the professional rights and contribute to create opportunities for public health graduates.

\section{Abbreviations}

BPKIHS: BP Koirala Institute of Health Sciences; CIST: Central Institute of Science and Technology; CMC: Chitwan Medical College; IOM: Institute of Medicine; KCHS: Karnali College of Health Science; MMC: Maharajgunj Medical Campus; MMIHS: ManMohan Memorial Institute of Health Sciences; MoHP: Ministry of Health and Population; NAMS: National Academy for Medical Science; NHPC: Nepal Health Professional Council; NIHS: Nepal Institute of Health Sciences; NOC: National Open College; PU: Purbanchal University; PoU: Pokhara University; VCHS: Valley College of Health Science; YHSA: Yeti Health Science Academy.

\section{Conflict of interest \\ None declared}

\section{Authors' contribution}

PK conceptualized the paper. PK wrote the first draft. SRM contributed in the revision. Both the authors read and approved the final version of the manuscript before submission.

\section{Acknowledgement}

We would like to thank the Department of Community Medicine and Public Health, Institute of Medicine and Nepal Development Society for the constant motivation to write this paper.

\section{References}

1. Government of Nepal, Ministry of Health and Population. Human Resource for Health Strategic Plan (2011-2015); 2012.

2. Government of Nepal, Ministry of Health and Population. Operating Manual for Department of Health Services; 2068.

3. Maskey M. Situational Analysis of Human Resource for Health. Britain Nepal Medical Trust; 2012.

4. Dixit H. The Quest for Health. Kathmandu: Educational Enterprises; 2009.

5. Tribhuvan University, Institute of Medicine. Curriculum of Bachelor in Public Health; 2011.

6. BP Koirala Memorial Institute of Health Sciences. Prospectus of MPH Program; 2014. 
7. Mahat A, Bezruchka SA, Gonzales V, Connell FA. Assessment of graduate public health education in Nepal and perceived needs of faculty and students. Hum Resour Health. 2013; 11: 16.

8. Institute of Medicine, Examination Section. PG Entrance Notice; 2014.

9. Department of Health Services, Ministry of Health and Population. Annual Report-2011/12; 2012.

10. World Health Organization. Modular Training Package on Effective Management of District Health Services; 2005.

11. Ministry of Health and Population, Department of Health Services. Job description of Employees; 1997.
12. Ministry of Health and Population. Nepal Health Service Act-2053 and Regulation-2055; 1996.

13. Ministry of Health and Population, Department of Health Services. National Health Policy; 2071.

14. Ministry of Health and Population, Department of Health Services. Service Operation Directives of Community Health Inspector; 2013.

15. MOHP, NHSSP. Review of National Health Policy; 1991. 